\title{
Literacy learning in a digital world
}

Julia Gillen and Natalia Kucirkova

We are all living in a world that is increasingly shaped by digital technologies. This can give us some exciting new opportunities in literacy teaching and learning, as explored in several projects worldwide, including a European programme on the Digital Literacy and Multimodal Practices of Young Children (DigiLitEY): http://digilitey.eu/. The project is built on the premise that digital technologies are fundamentally reshaping literacy and it is important to have an international dialogue with teachers and researchers about how these changes affect young children. Most young children are now interacting with various multimodal texts, often on portable screens such as tablets and smartphones. Rather than following the linear trajectory of print books, navigation can occur in more complex ways, involving sight, sound and touch. However, the role of adults in talking and interacting with children as they read and play is as vital for their learning as we have long known it is for print books (SeftonGreen, Marsh, Erstad and Flewitt (2016).

New technologies are being used to create more multimodal texts, expanding the modes of writing and reading to make better use of sounds and images, including moving images. Kress (2003, p.140) argues that the effect is a shift from "telling the world" to "showing the world". As adult educators, we can engage with ebooks and apps interactively, to access literature in dynamic ways. We can use media such as blogs, other social media and online radio stations and podcasts to connect with children and their families beyond the boundaries of the school walls. We can work with external collaborators to communicate for authentic purposes. There are certainly many opportunities to make learning more exciting for students and build upon some of the technologies they may be enjoying in homes and other settings beyond school.

Yet there are still many challenges, particularly created by the speed of change and proliferation of new devices. Some children and adults have difficulties in accessing all the latest technologies they might want and feel left behind. Teachers too vary in confidence and experience in using technology for learning purposes. We all face the issue that things change so much it is impossible for anybody to be equally expert in every kind of hardware, software, platform or social media service. 
In this chapter, based on our many years of experiences in classrooms with teachers, we share some suggestions and practices concerning digital technologies, that have come from teachers and children themselves.

We cannot adequately tackle all the digital technologies that appear in classrooms in one short chapter. From laptops to talking tins, from social media to coding, from Minecraft clubs to online music collaborations there are many technologies and ways to communicate that can be made relevant to literacy learning and teaching. We have decided to focus particularly on touchscreens, given their wide presence and versatility.

Before we delve into the details of effective touchscreens' use in early years and primary classrooms, we share some broader learning points from our on-going work with teachers and digital literacy.

First, it is important to accept that it is impossible to keep up with all the technology. Perhaps the most significant strategy in working with literacy in this digital age is model effective ways of learning oneself. That means collaborating with others, including children in the classroom, working out issues and problems openly. This is much better than concealing problem solving from the students, whatever their age, stage and capabilities. A corresponding recommendation is not to assume that children necessarily are adept with everything just because they appear accomplished with some tools. Unfortunately we have both witnessed occasions when children have been working while logged into somebody else's personalised learning pathway on a program, or even been struggling to find the on/off switch on the iPad while an adult has been telling us that the students already know how to do everything as they have learnt it at home.

Second, research shows that making effective use of technologies in the classroom is not only an issue about coming to grips with the practicalities of devices or software. The key issue is teachers' abilities to integrate the device with the school curriculum and classroom practice. Extremely helpful in this regard are school policies and ways of organising activities that promote a sharing culture. Research around the effective introduction of interactive whiteboards, for example, showed that schools which invested not only in the hardware but also in professional development and support, reported sustained and positive changes to their provision.

Third, teachers show us repeatedly that connecting with others beyond the school walls is extremely important. This can happen in many different ways and for various purposes. 
Parents and carers often value support from schools on helping their children protect themselves online. Some schools use blogs or text messages to connect with parents and caregivers to share news about what is going on in the classroom and what the children are achieving. This is often more effective if family members are involved in setting up the channels and communication preferences, and discuss together just how two-way dialogues can be used to support their children's learning and the home-school connection. One primary school we have been working with recently has its own app. Parents and other family members who use the app shared with us enthusiastically the benefits of being kept in touch with what their child's class is doing, opening the app to access all kinds of information, and, most crucially, to be involved together with their children in using the app at weekends and holidays. Only by making the content genuinely immediate and interesting can this be achieved. It is also very important to this school's community that it could be accessed by a smartphone, as laptops and PCs are relatively rare in their family homes. Not all schools will have the means to develop their own apps but there are several apps that schools can adopt for their use. For example, a popular app called Easy Peasy ${ }^{\mathrm{TM}}$ sends parents regular reminders to engage with their children in educational activities. Teachers can encourage parents to use apps such as Easy Peasy to enrich the communication with their children and the work they do in the classroom.

Apps and regular updates via blogs can be remarkably effective also for teachers and trainee teachers to discuss professional development. For example, through Twitter or Facebook groups, or through watching and commenting on YouTube videos or Instagram content, teachers can share inspirational practice and comment on evidence-informed approaches. Fourth, it is important to remember that children's experiences, skills and preferences with technologies are heterogeneous, multiple and diverse. Although some children might appear more skilled in using a specific device than an adult, this is often due to their willingness to explore and try out new things. The myth that children are born as digital natives has been shown by researchers as over-simplistic; there are many cultural, socio-economic and individual differences among children when it comes to technology use. Teachers are uniquely positioned to recognise these differences and just as they do with many other resources in the classroom, they can tailor provision to support children's varied interests and competencies. 
In the next section, we share some case study examples illustrating these four points and other observations in relation to digital literacy and touchscreens.

\section{Touchscreens in primary classrooms}

Touchscreens is an umbrella term we use to subsume touch-manipulable technologies, including tablets and interactive whiteboards (IWBs). By tablets we mean those made by Apple (called iPads) or other companies such as Samsung, Eriksson, Acer or Microsoft). Some of these technologies are part and parcel of young children's "early technoliteracies" (Wohlwend, 2010, p.145), as many homes have smartphones and tablets. But other kinds of touchscreens and, of course, many of the uses to which tablets for example might be put to in the classroom, could be entirely new to children.

Touchscreens can be used for whole class, small group, pair and independent learning. It takes careful planning to consider how touchscreens can be used at different times, for distinct purposes and what kind of direct instruction or "scaffolding" is needed by teachers and other people in the classroom. Large wall-based interactive whiteboards (IWBs) are most effectively used for whole class or large group interactions, for example through sharing learning objects, explaining how a session is going to work and introducing key resources and concepts. The affordances of an IWB (that is how its features can be used in practice) can be perceived and deployed in various imaginative ways.

For example, a Year 3 (children aged 7-8 years) teacher used an IWB in a sequence of lessons focussing on writing instructional texts: recipes (Gillen, Kleine Staarman, Littleton, Mercer \& Twining, 2007). The previous day the pupils had made pancake batter, the teacher had taken some digital photographs of their activities and now displayed them in a whole class labelling activity. Individual pupils came to the front to write and attach labels to these images appropriately, supported through discussion. The teacher then moved to using the "block-reveal" facility, that is covering up pre-written elements. He encouraged the class to make predictions about the stages of the recipe and precise lexical and grammatical terms. Many connections to previous learning were made, such as keying in to the activities of the day before, and explicit identification of verbs and their functions in the recipe genre. This is an example of moving beyond IWBs as a "presentational technology". Rather, this exemplifies a dialogic style of teaching, where effective talking and listening is understood to be at the heart of literacy pedagogy (Mercer and Hodgkinson, 2008). 
By tailoring the content to the needs and interests of the children in their classrooms, the teachers can ignite children's interest in traditional subjects, increase children's motivation to explore stories and other educational content and combine personal interest with wider narratives. Kucirkova (2014) describes a series of cross-curriculum case studies about how the Foundation, Year1 and Year2 teachers from one UK primary school used a story-making app (called Our Story) to personalise their lessons.

In one session, for example, the Foundation teacher (children aged 5 years) decided to personalise the story Where is Spot? written by Eric Hill (see Kucirkova, Willans \& Cremin, 2013). Instead of the dog hiding in the house, the teacher created a hybrid story, which contained Hill's original narrative but combined it with pictures of the children in the classroom. The digital story was created with the Our Story app, which helped the teacher insert children's photographs in-between the 'Where is Spot?' story. In the final book, there were several personalised elements, for instance, instead of Spot hiding underneath the staircase, there was a picture of group of children. The final digital story was shared with the children in a classroom assembly and contained digital images and audio recordings as well as text. Children who appeared in the pictures were encouraged to write their name underneath the photographs, with attention paid to correct spelling and capital letters for personal names. The children loved the surprise element in the book and felt confident talking about the story when they saw familiar faces of their friends inside the new multimodal book. The teacher succeeded in combining several early learning goals in this activity, including speech (audio-recorded sounds in the digital story) with writing and supporting children's understanding of the difference between print and pictures. The creation process was seamless and quick and yet the final product had a polished quality that the children and their parents have become accustomed to in commercial media. It is these kinds of creative experiences that expand expectations of what can be achieved when moving beyond traditional pen and paper activities.

Of course, pen and paper activities remain extremely important in our literacy classrooms. Touchscreens can be used to support traditional literacy activities such as the writing of narratives. We observed one mixed year 5 and 6 class working on the topic of The Highwayman, based on the narrative poem by Alfred Noyes, illustrated by Charles Keeping. The lesson we observed began with a consolidation of earlier activities, organised by the teacher with the IWB, including through showing an extract from a drama exercise undertaken by the children the day before. Shared understanding of the task for this day was 
achieved through discussion structured through the plan visible to all on the board. Then the children began working in pairs, first identifying some relevant characteristics in texts that were shared with them in hard copy, using highlighter pens. They then used their tablets to research facts about highwaymen. The children were confident in using a range of search strategies, explicitly recalling the "Golden Rules" of the classroom. These included staying on task, not clicking on advertisements and making bullet pointed lists. They demonstrated considerable experience in internet searching, with quite sophisticated understandings of how to judge the quality of websites. This was appropriately checked by the teacher: "Are all the websites you're looking at 100\% reliable?" she asked the class at one point, referring implicitly to earlier discussions about internet safety and quality. The children demonstrated the capacity to research in autonomous, cooperative pairs, and so diverse findings emerged across the class group, creating resources for further productive whole group discussion. Another notable characteristic of this pedagogic event was the range of technologies around the children, with the digital blended into their learning environments: the iPads and their robust cases took their places alongside not just paper and pens but their shared "punctuation pyramids" and own "magpie notebooks". It takes time and coherent planning to embed such technological complexity into a class group effectively.

Other examples we have observed involve the creation of digital products alongside pen and paper in the classroom. For example a Year 5 class crafted traditional narratives, based upon the popular game app "Bike Baron." The children paid considerable attention to spelling punctuation and grammar, as well as the ingredients of crafting an effective narrative. In the same project they created multimodal texts using the app "Strip Designer" with their tablets. Here they understood that the comic format demanded a very different focus of attention. They needed to identify several (but no more) visually dramatic moments from their story, arrange them and use brief textual speech bubbles and/or captions. Key values varied from the pen and paper stories, but they were both challenging. The teacher was equally adept at discussing the two kinds of texts at appropriate times. For example the text narratives demanded attention to curriculum learning goals, including spelling, punctuation, grammar and textual cohesion. The comic format on the other hand required great care in the selection of key images, layout, crafting of effective yet brief texts in speech bubbles and captions, and so on. Understanding the particular constraints and opportunities of each genre was made more meaningful through the contrast. In this same classroom another particularly effective practice of the IWB in whole group discussion was demonstrated. When this teacher asked 
all students to pause for a moment, he often projected the screen from a single student's tablet onto the IWB at the front, as a significant shared resource for discussion.

As we have mentioned, a key difference between IWBs and tablets is that the former is extremely unlikely (to say the least!) to be encountered by children in their homes, while tablets are extremely common. Therefore, Table 1 summarises what we consider to be the key features of tablets and their values for teaching. This table is offered as a stimulus for thinking about the actual and potential activities associated with a specific teacher, or, at a higher level, in school practices and perhaps policies.

Table 1: Reasons for using tablets in the literacy classroom

\begin{tabular}{|c|c|}
\hline Relevant features of the device or of its use & $\begin{array}{l}\text { Key value for teaching } \\
\text { (pedagogical justifications) }\end{array}$ \\
\hline $\begin{array}{l}\text { Socio-cultural acceptance } \\
\text { (popularity of the device in the } \\
\text { society) }\end{array}$ & $\begin{array}{l}\text { Motivation } \\
\text { Engagement } \\
\text { Ownership } \\
\text { Bridging home-school divide }\end{array}$ \\
\hline $\begin{array}{l}\text { - Access to profile, contacts } \\
\text { - Possibility to personalise or } \\
\text { customise the experience }\end{array}$ & $\begin{array}{l}\text { Personalised learning } \\
\text { Bridging home-school divide }\end{array}$ \\
\hline $\begin{array}{l}\text { - Iconic navigation } \\
\text { - Simple user interface } \\
\text { - Availability of a large number of } \\
\text { apps } \\
\text { - Multimedia, compactness }\end{array}$ & $\begin{array}{l}\text { Independent learning } \\
\text { Multimedia learning } \\
\text { Variety of engagement } \\
\text { possibilities }\end{array}$ \\
\hline $\begin{array}{l}\text { - Portable (mobile) } \\
\text { - } \quad \text { Light-weight }\end{array}$ & In-and out-of-classroom use \\
\hline
\end{tabular}


- $\quad$ Touch manipulation

- Immediate feedback

\section{Touchscreens supporting literacy education}

So far, our examples have centered on the affordances of the hardware and context of use. We now zoom in on the content of the activities we have observed and the different software programmes (also called applications or 'apps') that we noticed as useful for the teachers we worked with.

\section{Personalised apps}

One exciting possibility for enriching the literacy classroom is to use touchscreens to support personalised education. This can be facilitated by the customisation and personalisation options available in several apps, for example Our Story ${ }^{\mathrm{TM}}$, Puppet Pals ${ }^{\mathrm{TM}}$ or Grandma's Great Gourd ${ }^{\mathrm{TM}}$. Customisation options include the possibility to adjust the settings according to a set of criteria, such as for example the child's age, gender or reading level or interests (e.g., choosing the pirate as the main story character). Open-ended apps that allow for children's own- personalised- input are very useful in supporting children's creative and agentic expressions but also classroom talk among peers.

\section{Literacy apps}

Literacy apps include apps which support discrete literacy-related skills such as letter recognition and spelling, but also digital books that present traditional stories in a new format. Such apps can offer children a story experience that complements or is over and above a traditional book reading experience. When selecting literacy apps, we recommend choosing those that hybridise several media into one, but that do not privilege video material over written text and quality illustrations. When choosing the literacy apps for your lesson, apply the criteria that you would do for printed books, but in addition, consider the following:

A. Remember that good digital books do not replicate a printed book on the screen but combine a book's qualities with the key assets of tablets - involving multimedia, being customisable, and supporting authoring and sharing of user-generated content. 
B. Read not only the app's short descriptions of its developers, but also users' reviews. There are several teachers-curated websites that provide reviews of the latest apps and digital books. Teachers with Apps (http://www.teacherswithapps.com/) is our favourite review site. There are also several expert-led organisations that regularly review children's apps, see for example: Common sense media (https://www.commonsensemedia.org/app-reviews), and, Children's Technology Review (http://reviews.childrenstech.com/ctr/home.php?category=Library+Apps\&quickfind= Library+Apps\&page=1).

C. You could begin your selection process by looking into digital books that have received an independent award. In the UK we have the UKLA Children's Digital Book Award (https://ukla.org/awards/ukla-digital-book-award), judged by a panel of teachers. You can be sure that an app that receives this award has been used effectively in schools and enjoyed by children. The criteria used to evaluate children's digital books are freely available on the UKLA's website and might be a good reference point for your own judging of digital books/literacy apps: https://ukla.org/forms/view/digital-book-award-form. Other expert-based international awards include: the KAPI Awards (http://kapiawards.com/) or Bologna Children's Digital Book Award (http://childrenstech.com/bolognaragazzidigital). The European DigiLitEY programme provides resources for teachers such as "Which digital books work best in the classroom?" (http://digilitey.eu/publications/information-for-teachers/.)

D. Check that the multimedia features (music, voiceovers, short videos embedded in the book) do not disrupt the children's independent or paired reading. Many free apps contain in-app purchases or ads and it is better to pay $£ 3-4$ for an app upfront then to worry about these extra paid features being inadvertently or otherwise activated by the children. 
Finally.....

Be part of it...

There is a growing research base and bank of resources developed for pre- and primaryschool-teachers to empower them in evaluating the value of touchscreens for their classrooms. The UK's National Literacy Trust has developed an "App Guide" (http://literacyapps.literacytrust.org.uk/) to help early years educators choose appropriate apps for supporting reading for pleasure with 0-5-year old children. The more teachers participate in the co-creation of apps and methods to use them, the more likely it is that touchscreens will play an effective pedagogical role in early education. 
References:

Gillen, J., Staarman, J. K., Littleton, K., Mercer, N., \& Twiner, A. (2007). A “learning revolution"? Investigating pedagogic practice around interactive whiteboards in British primary classrooms. Learning, Media and Technology, 32(3), 243-256.

Kress, G. (2003) Literacy in the new media age. London: Routledge.

Kucirkova, N. (2014). iPads and Tablets in the Classroom: Personalising Children's Stories (Vol. 41). UKLA.

Kucirkova, N., Willans, D. and Cremin, T. (2013) Spot the Dog with iPads, spot the difference, English 4-11 Leicester UKLA and EA

Mercer, N. \& Hodgkinson, S. (2008) Exploring talk in school. London: SAGE.

Noyes, A. \& Keeping, C. (2013) The Highwayman New Edn. Oxford: Oxford University Press.

Sefton-Green, J., Marsh, J., Erstad, O., and Flewitt, R. (2016). Establishing a Research Agenda for the Digital Literacy Practices of Young Children: a White Paper for COST Action IS1410. [Accessed: http:// digilitey.eu]

Wohlwend, K. E. (2010). A is for avatar: Young children in literacy 2.0 worlds and literacy 1.0 schools. Language Arts, 88(2), 144. 